\title{
Time-Domain Synthesis Problem involving I-Function of Several Variables
}

\author{
${ }^{1}$ Dr. S. S. Shrivastava, ${ }^{2}$ PinkeySikarwar \\ ${ }^{12,}$ Department of Mathematics Govt. P.G. College, shahdol( M.P)
}

Abstract: The object of this paper is to evaluate an integral involving Bessel polynomial and I-function of several variables and employ it to obtain a particular solution of the general solution derived in this paper of the classical problem known as the, "Time-domain Synthesis Problem", occurring in electrical network theory.

Keywords: Time-domain Synthesis Problem, electrical network theory,Bessel polynomial,I-Function of several variables.

\section{Introduction:}

The I-function of several variables introduced by Sharma and Ahmed given in [1], will be defined and represented as follows:

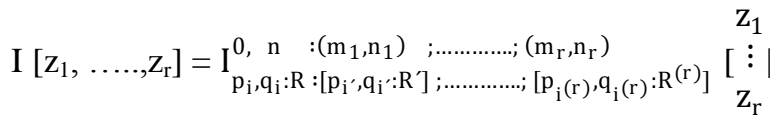

$$
\begin{aligned}
& {\left[\left(a_{j} ; \alpha_{j}^{\prime}, \ldots, \alpha_{j}^{(r)}\right)_{1, n}\right],\left[\left(a_{j i} ; \alpha_{j i}^{\prime}, \ldots, \alpha_{j i}^{(r)}\right)_{n+1, p_{i}}\right]:}
\end{aligned}
$$

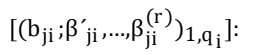

$$
\begin{aligned}
& {\left[\left(c^{\prime}{ }_{j}, \gamma_{j}^{\prime}\right)_{1, n_{1}}\right],\left[\left(c^{\prime} j^{\prime}, \gamma^{\prime}{ }_{j i}\right)_{n_{1}+1, p_{i}}\right] ; \ldots . . ;\left[\left(c_{j}^{(r)}, \gamma_{j}^{(r)}\right)_{1, n_{r}}\right],\left[\left(c_{j i}^{(r)}(r), \gamma_{j i}^{(r)}(r)\right)_{n_{r}+1, p_{i}(r)}\right]}
\end{aligned}
$$

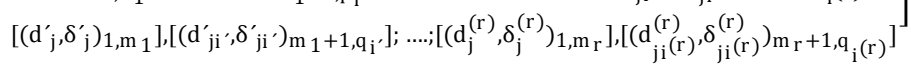

$$
\begin{aligned}
& =\frac{1}{(2 \pi \omega)^{\mathrm{r}}} \int_{\mathrm{L}_{1}} \ldots \int_{\mathrm{L}_{\mathrm{r}}} \phi_{1}\left(\xi_{1}\right) \ldots \phi_{\mathrm{r}}\left(\xi_{\mathrm{r}}\right) \psi\left(\xi_{1}, \ldots, \xi_{\mathrm{r}}\right) \mathrm{z}_{1} \xi_{1} \ldots \mathrm{z}_{\mathrm{r}} \xi_{\mathrm{r}} \mathrm{d} \xi_{1} \ldots \mathrm{d} \xi_{\mathrm{r}} \text {, }
\end{aligned}
$$

where

$$
\begin{aligned}
& \square=\square(1), \\
& \phi_{\mathrm{k}}\left(\xi_{\mathrm{k}}\right)=\frac{\Pi_{\mathrm{j}=1}^{\mathrm{m}} \Gamma\left(\mathrm{d}_{\mathrm{j}}^{(\mathrm{k})}-\delta_{\mathrm{j}}^{(\mathrm{k})} \xi_{\mathrm{k}}\right) \prod_{\mathrm{j}=1}^{\mathrm{n}} \Gamma\left(1-\mathrm{c}_{\mathrm{j}}^{(\mathrm{k})}+\gamma_{\mathrm{j}}^{(\mathrm{k})} \xi_{\mathrm{k}}\right)}{\left.\sum_{\mathrm{i}}^{\mathrm{R}(\mathrm{k})}=1 \prod_{\mathrm{j}=\mathrm{m}_{\mathrm{k}}+1}^{\mathrm{q}_{\mathrm{i}}^{(\mathrm{k})}} \Gamma\left(1-\mathrm{d}_{\mathrm{ji}}^{(\mathrm{k})}+\delta_{\mathrm{ji}}^{(\mathrm{k})} \xi_{\mathrm{k}}\right) \prod_{\mathrm{j}=\mathrm{n}_{\mathrm{k}}+1}^{\mathrm{p}_{\mathrm{i}}} \Gamma\left(\mathrm{c}_{\mathrm{ji}}^{(\mathrm{k})}-\gamma_{\mathrm{ji}}^{(\mathrm{k})} \xi_{\mathrm{k}}\right)\right]},
\end{aligned}
$$

$\forall \mathrm{k} \varepsilon\{1, \ldots, \mathrm{r}\}$

$$
\psi\left(\xi_{1}, \ldots, \xi_{r}\right)=\frac{\prod_{j=1}^{\mathrm{n}} \Gamma\left(1-\mathrm{a}_{\mathrm{j}}+\sum_{\mathrm{k}=1}^{\mathrm{r}} \alpha_{\mathrm{j}}^{(\mathrm{k})} \xi_{\mathrm{k}}\right)}{\sum_{\mathrm{i}=1}^{\mathrm{R}}\left[\prod_{\mathrm{j}=\mathrm{n}+1}^{\mathrm{p}_{\mathrm{i}}} \Gamma\left(\mathrm{a}_{\mathrm{ji}}-\sum_{\mathrm{k}=1}^{\mathrm{r}} \alpha_{\mathrm{ji}}^{(\mathrm{k})} \xi_{\mathrm{k}}\right) \prod_{\mathrm{j}=1}^{\mathrm{q}_{\mathrm{i}}} \Gamma\left(1-\mathrm{b}_{\mathrm{ji}}+\sum_{\mathrm{k}=1}^{\mathrm{r}} \beta_{\mathrm{ji}}^{(\mathrm{k})} \xi_{\mathrm{k}}\right)\right.}
$$

in (1), $\mathrm{k}$ in the superscript $(\mathrm{k})$ stands for the number of primes; and $\mathrm{z}_{1}, \ldots, \mathrm{z}_{\mathrm{r}}$ are not equal to zero and an empty product is interpreted as unity.

Suppose, as usual, that the parameters

$a_{j}, j=1, \ldots, n ; a_{j i}, j=n+1, \ldots, p_{i} ; b_{j i}, j=1, \ldots, q_{i} ; c_{j}^{(k)}, j=1 \ldots, n_{k}$;

$c_{j i}^{(k)}, j=n_{k}+1, \ldots, p_{i}(k)$;

$d_{j}^{(k)}, j=1 \ldots, m_{k} ; d_{j i}^{(k)}, j=m_{k}+1, \ldots, q_{i}(k)$;

$\forall \mathrm{i} \in\{1, \ldots, \mathrm{R}\}, \forall \mathrm{i}^{(\mathrm{k})} \in\left\{1, \ldots, \mathrm{R}^{(\mathrm{k})}\right\} ; \forall \mathrm{k} \in\{1, \ldots, \mathrm{r}\}$

are complex numbers, and all the $\alpha$ 's, $\beta$ 's, $\gamma^{\prime}$ s and $\delta$ 's are assumed to be positive real numbers for standardization purpose such that

$$
\begin{gathered}
\mathrm{U}_{\mathrm{k}}=\sum_{\mathrm{j}=1}^{\mathrm{n}} \alpha_{\mathrm{j}}^{(\mathrm{k})}+\sum_{\mathrm{j}=\mathrm{n}+1}^{\mathrm{p}_{\mathrm{i}}} \alpha_{\mathrm{ji}}^{(\mathrm{k})}+\sum_{\mathrm{j}=1}^{\mathrm{n}_{\mathrm{k}}} \gamma_{\mathrm{j}}^{(\mathrm{k})}+\sum_{\mathrm{j}=\mathrm{n}_{\mathrm{k}}+1}^{\mathrm{p}_{\mathrm{i}}(\mathrm{k})} \gamma_{\mathrm{ji}}^{(\mathrm{k})} \\
-\sum_{\mathrm{j}=1}^{\mathrm{q}_{\mathrm{i}}} \beta_{\mathrm{ji}}^{(\mathrm{k})}-\sum_{\mathrm{j}=1}^{\mathrm{m}_{\mathrm{k}}} \delta_{\mathrm{j}}^{(\mathrm{k})}-\sum_{\mathrm{j}=\mathrm{m}_{\mathrm{k}}+1}^{\mathrm{q}_{\mathrm{i}}(\mathrm{k})} \delta_{\mathrm{ji}}^{(\mathrm{k})} \leq 0
\end{gathered}
$$




$$
\begin{gathered}
\mathrm{V}_{\mathrm{k}}=\sum_{\mathrm{j}=1}^{\mathrm{n}} \alpha_{\mathrm{j}}^{(\mathrm{k})}-\sum_{\mathrm{j}=\mathrm{n}+1}^{\mathrm{p}_{\mathrm{i}}} \alpha_{\mathrm{ji}}^{(\mathrm{k})}+\sum_{\mathrm{j}=1}^{\mathrm{n}_{\mathrm{k}}} \gamma_{\mathrm{j}}^{(\mathrm{k})}-\sum_{\mathrm{j}=\mathrm{n}_{\mathrm{k}}+1}^{\left.\mathrm{p}_{\mathrm{i}} \mathrm{k}\right)} \gamma_{\mathrm{ji}}^{(\mathrm{k})} \\
-\sum_{\mathrm{j}=1}^{\mathrm{q}_{\mathrm{i}}} \beta_{\mathrm{ji}}^{(\mathrm{k})}+\sum_{\mathrm{j}=1}^{\mathrm{m}_{\mathrm{k}}} \delta_{\mathrm{j}}^{(\mathrm{k})}-\sum_{\mathrm{j}=\mathrm{m}_{\mathrm{k}}+1}^{\mathrm{q}_{\mathrm{i}}(\mathrm{k})} \delta_{\mathrm{ji}}^{(\mathrm{k})}>0,
\end{gathered}
$$

$\forall \mathrm{i} \in\{1, \ldots, \mathrm{R}\}, \forall \mathrm{i}^{(\mathrm{k})} \in\left\{1, \ldots, \mathrm{R}^{(\mathrm{k})}\right\} ; \forall \mathrm{k} \in\{1, \ldots, \mathrm{r}\}, \mathrm{p}_{\mathrm{i}}, \mathrm{q}_{\mathrm{i}}, \mathrm{p}_{\mathrm{i}}(\mathrm{k})$,

$\mathrm{q}_{\mathrm{i}}(\mathrm{k}), \mathrm{n}, \mathrm{n}_{\mathrm{i}}(\mathrm{k})$ and $\mathrm{m}_{\mathrm{i}}(\mathrm{k}), \forall \mathrm{i} \in\{1, \ldots, \mathrm{R}\}, \forall \mathrm{i}^{(\mathrm{k})} \in\left\{1, \ldots, \mathrm{R}^{(\mathrm{k})}\right\}$;

$\forall \mathrm{k} \in\{1, \ldots, \mathrm{r}\}$ are non-negative integers such that $\mathrm{p}_{\mathrm{i}} \geq \mathrm{n} \geq 0, \mathrm{p}_{\mathrm{i}}(\mathrm{k}) \geq \mathrm{n}_{\mathrm{i}}(\mathrm{k}) \geq 0, \mathrm{q}_{\mathrm{i}} \geq 0, \mathrm{q}_{\mathrm{i}}(\mathrm{k}) \geq 0, \forall \mathrm{i} \in$ $\{1, \ldots, \mathrm{R}\}, \forall \mathrm{i}^{(\mathrm{k})} \in\left\{1, \ldots, \mathrm{R}^{(\mathrm{k})}\right\}$ and $\forall \mathrm{k} \in\{1, \ldots, \mathrm{r}\}$.

The definition of the multivariable I-function given by equation (1) will however has a meaning even if some of these quantities are zero. The sequences of parameters in (1) are such that none of the poles of the integrand coincide, that is, the poles of the integrand in (1) are simple. The contour $\mathrm{L}_{\mathrm{k}}$ in the complex $\xi_{\mathrm{k}}$-plane is of the Mellin-Barnes type which runs from $\square \infty \infty$ to $+\omega \infty$ with indentations, if necessary, to ensure that all the poles of $\Gamma\left(\mathrm{d}_{\mathrm{j}}^{(\mathrm{k})}-\delta_{\mathrm{j}}^{(\mathrm{k})} \xi_{\mathrm{k}}\right), \mathrm{j}=1, \ldots, \mathrm{m}_{\mathrm{k}}$ are separated from those of $\Gamma\left(1-\mathrm{c}_{\mathrm{j}}^{(\mathrm{k})}+\gamma_{\mathrm{j}}^{(\mathrm{k})} \xi_{\mathrm{k}}\right), \mathrm{j}=1, \ldots, \mathrm{m}_{\mathrm{k}}$ and $\Gamma\left(1-\mathrm{a}_{\mathrm{j}}^{(\mathrm{k})}+\sum_{\mathrm{k}=1}^{\mathrm{r}} \mathrm{a}_{\mathrm{j}}^{(\mathrm{k})} \xi_{\mathrm{k}}\right), \mathrm{j}=1, \ldots, \mathrm{n} ; \forall \mathrm{k} \in[1, \ldots, \mathrm{r}]$.

It is known that the multiple Mellin-Barnes contour integral representing the multivariable I-function (1.3.4) converges absolutely under the condition (3), when

$$
\left|\arg :\left(\mathrm{z}_{\mathrm{k}}\right)\right|<\frac{1}{2} \mathrm{~V}_{\mathrm{k}} \pi, \forall \mathrm{k} \in[1, \ldots, \mathrm{r}]
$$

the point $\mathrm{z}_{\mathrm{k}}=0 ; \mathrm{k}=1, \ldots, \mathrm{r}$ and various exceptional parameter values, being tacitly excluded.

Furthermore, we may establish the asymptotic expansions in the following convenient form:

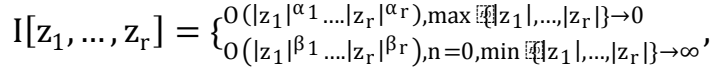

where, with $\mathrm{k}=1, \ldots, \mathrm{r}$;

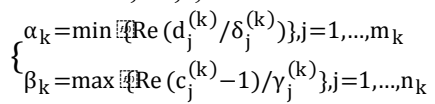

provided that each of the inequalities in (2), (3) and (4) holds.

Bessel polynomial [2, p. 213, (2)]:

$$
\begin{aligned}
\mathrm{y}_{\mathrm{n}}(\mathrm{x} ; \mathrm{a}, \mathrm{b})=\sum_{\mathrm{r}=0}^{\mathrm{n}} \frac{(-\mathrm{n})_{\mathrm{r}}(\mathrm{a}+\mathrm{n}-1)_{\mathrm{r}}}{\mathrm{r} !}\left(-\frac{\mathrm{x}}{\mathrm{b}}\right)^{\mathrm{r}} \\
={ }_{2} \mathrm{~F}_{0}\left[-{ }_{-}^{-\mathrm{n}, \mathrm{a}+\mathrm{n}-1 ;}-\mathrm{x} / \mathrm{b}\right] .
\end{aligned}
$$

Orthogonality property of Bessel polynomials [2, p. 215, (14)]:

$$
\int_{0}^{\infty} x^{a-2} e^{-\frac{1}{x}} y_{m}(x ; a, 1) d x=\frac{(-1)^{n} n !(n+a-1) \pi}{\Gamma(a+n) \Gamma(2 n+a-1) \sin \pi a} \delta_{m, n},
$$

where Re a $<1 \square m$ h $\square$.

$$
\int_{0}^{\infty} \mathrm{x}^{\sigma-1} \mathrm{e}^{-\frac{1}{\mathrm{x}} \mathrm{y}_{\mathrm{n}}(\mathrm{x} ; \mathrm{a}, 1) \mathrm{dx}=\frac{\Gamma(-\sigma-\mathrm{n}) \Gamma(\mathrm{a}-\sigma-1+\mathrm{n})}{\Gamma(\mathrm{a}-\sigma-1)}}
$$

where $\operatorname{Re} \square<0, \operatorname{Re}(\mathrm{a} \square)<2, \sigma \neq-1,-2,-3, \ldots$

The integral (7) can easily established by expressing the Bessel Polynomial in the integrand as its series representation (5), interchainging the order of integration and summation, evaluating the resulting integral with the help of [3, p. 313(16)], using Gauss's theorem [4, p.104, (46)] and [4, p.3(3)].

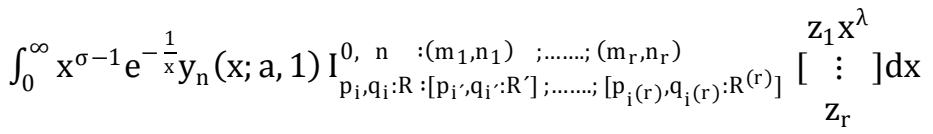

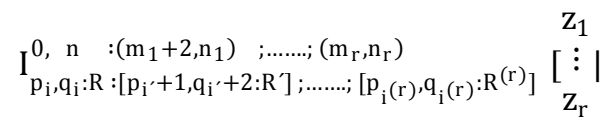

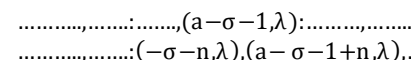

$$
\begin{aligned}
& \text { ], (8) }
\end{aligned}
$$


provided that $\operatorname{Re} \square<0, \operatorname{Re}(\mathrm{a} \square)<2, \sigma \neq-1,-2,-3, \ldots$ and $\left|\arg \left(\mathrm{z}_{\mathrm{k}}\right)\right|<\frac{1}{2} \mathrm{~V}_{\mathrm{k}} \pi, \forall \mathrm{k} \in[1, \ldots, \mathrm{r}]$, where $\mathrm{V}$ is given in (3).

Proof:

To establish (8), expressing the I-function in the integrand as a Mellin-Barnes type integral (1) and interchainging the order of integrations which is justified due to the absolute convergence of the integrals involved in the process, evaluating the inner-integral with the help of (7) and using the definition of I-function, we arrive at (8).

\section{Solution of the Time-Domain Synthesis Problem of Signals:} [5, p.139]:

The classical time-domain synthesis problem occurring in electrical network theory is stated as follows

Given an electrical signal described by a real valued conventional function $\mathrm{f}(\mathrm{t})$ on $0<\mathrm{t}<\square$, construct an electrical network consisting of finite number of components R, C and I which are all fixed, linear and positive, such that the output of $\mathrm{f}_{\mathrm{N}}(\mathrm{t})$, resulting from a delta-function $\square(\mathrm{t})$ approximates $\mathrm{f}(\mathrm{t})$ on $0<\mathrm{t}<\square$ Th some sense.

In order to obtain a solution of this problem, we expand the function $\mathrm{f}(\mathrm{t})$ into a convergent series:

$$
\mathrm{f}(\mathrm{t})=\sum_{\mathrm{n}=0}^{\infty} \psi_{\mathrm{n}}(\mathrm{t})
$$

of real-valued function $\psi_{n}(t)$. Let every partial sum

$$
\mathrm{f}_{\mathrm{N}}(\mathrm{t})=\sum_{\mathrm{n}=0}^{\mathrm{N}} \Psi_{\mathrm{n}}(\mathrm{t}), \mathrm{N}=0,1,2, \ldots
$$

possess the two properties:

(i) $\mathrm{f}_{\mathrm{N}}(\mathrm{t})=0$, for $\square \square \mathrm{t}<0$.

(ii) The laplace transform $\mathrm{F}_{\mathrm{N}}(\mathrm{s})$ of $\mathrm{f}_{\mathrm{N}}(\mathrm{t})$ is a rational function having a zero at $\mathrm{s}=\square \square$ and all its poles in the lefthalf s-plane, except possibly for a simple pole at the origin.

After choosing $\mathrm{n}$ in (10) sufficiently large to satisfy whatever approximation criterion is being used, an orthonormal series expansion may be employed. The Bessel polynomial transformation and (5) yields an immediate solution in the following form:

where

$$
f(t)=\sum_{n=0}^{\infty} c_{n} t^{(a-2) / 2} e^{-1 / 2 t} y_{n}(t ; a, 1),
$$

$c_{n}=(-1)^{n} \frac{\Gamma(a+n) \Gamma(2 n+a-1) \sin \pi a}{n !(n+a-1) \pi} \int_{0}^{\infty} f(t) t^{(a-2)} e^{-1 / 2 t} y_{n}(t ; a, 1) d t$,

where Re a $<1 \square$ n.

This case is an example of the use of hypergeometric integral in an orthonormal series expansion.

\section{Particular Solution of the Problem:}

The particular solution of the problem in terms of I-function of several variables is as follows:

$$
\begin{aligned}
& f(t)=\frac{\sin \pi a}{\pi} \sum_{n=0}^{\infty}(-1)^{n} \frac{\Gamma(a+n) \Gamma(2 n+a-1)}{n !(n+a-1)} t^{(a-2) / 2} e^{-1 / 2 t} y_{n}(t ; a, 1)
\end{aligned}
$$

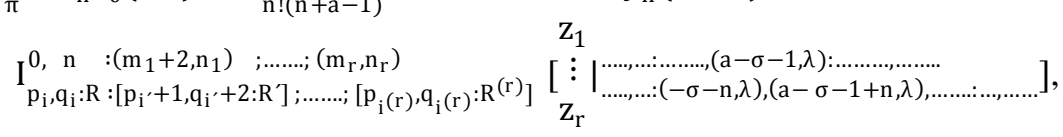

provided that $\operatorname{Re} \square<0, \operatorname{Re}(\mathrm{a} \square)<2, \sigma \neq-1,-2,-3, \ldots$. and $\left|\arg \left(\mathrm{z}_{\mathrm{k}}\right)\right|<\frac{1}{2} \mathrm{~V}_{\mathrm{k}} \pi, \forall \mathrm{k} \in[1, \ldots, \mathrm{r}]$, where $\mathrm{V}_{\mathrm{k}}$ is given in (3).

\section{Proof:}

Let us consider

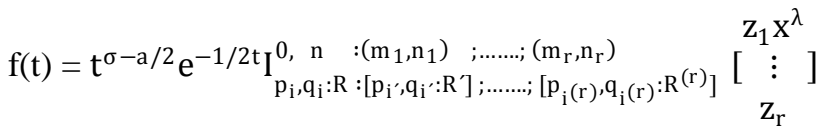

$$
\begin{aligned}
& =\sum_{n=0}^{\infty} c_{n} t^{(a-2) / 2} e^{-1 / 2 t} y_{n}(t ; a, 1) .
\end{aligned}
$$

Equation (13) is valid, since $f(t)$ is continuous and of bounded variation in the open interval $(0, \square)$. 

we get

Multiplying both sides of (13) by $\mathrm{t}^{(\mathrm{a}-2) / 2} \mathrm{e}^{-1 / 2 \mathrm{t}} \mathrm{y}_{\mathrm{m}}(\mathrm{t} ; \mathrm{a}, 1)$ and integrating with respect to $\mathrm{t}$ from 0 to $\square$,

$$
\begin{aligned}
& \int_{0}^{\infty} \mathrm{t}^{\sigma-1} \mathrm{e}^{-1 / \mathrm{t}} \mathrm{y}_{\mathrm{n}}(\mathrm{t} ; \mathrm{a}, 1) \mathrm{I}_{\mathrm{p}_{\mathrm{i}}, \mathrm{q}_{\mathrm{i}}: \mathrm{R}:\left[\mathrm{p}_{\mathrm{i}}, \mathrm{q}_{\mathrm{i}}: \mathrm{R}\right] ; \ldots \ldots . ;\left[\mathrm{p}_{\mathrm{i}}(\mathrm{r}), \mathrm{q}_{\mathrm{i}}(\mathrm{r}): \mathrm{R}^{(\mathrm{r})}\right]}\left[\begin{array}{c}
\mathrm{z}_{1} \mathrm{t}^{\lambda} \\
\vdots \\
\mathrm{z}_{\mathrm{r}}
\end{array}\right] \mathrm{dt} \\
& =\sum_{\mathrm{n}=0}^{\infty} \mathrm{c}_{\mathrm{n}} \int_{0}^{\infty} \mathrm{t}^{(\mathrm{a}-2)} \mathrm{e}^{-1 / \mathrm{t}} \mathrm{y}_{\mathrm{m}}(\mathrm{t} ; \mathrm{a}, 1) \mathrm{dt} .
\end{aligned}
$$

Now using (8) and (6), we get

$$
\begin{aligned}
& \mathrm{c}_{\mathrm{m}}=\frac{(-1)^{\mathrm{m}} \Gamma(\mathrm{a}+\mathrm{m})(2 \mathrm{~m}+\mathrm{a}-1) \sin \pi \mathrm{a}}{\mathrm{m} !(\mathrm{m}+\mathrm{a}-1) \pi}
\end{aligned}
$$

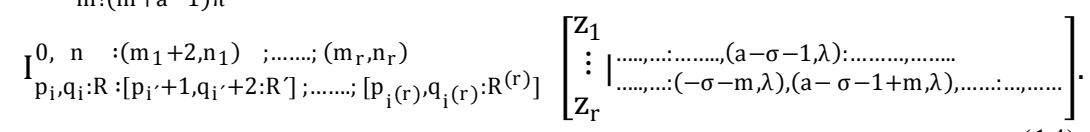

From (13) and (14), the solution (12) follows immediately.

\section{Special Case:}

On choosing $r=1$ and $R=r$ in (12), we get following solution in terms of I-function of one variable:

$$
\begin{aligned}
& \mathrm{f}(\mathrm{t})=\frac{\sin \pi \mathrm{a}}{\pi} \sum_{\mathrm{n}=0}^{\infty}(-1)^{\mathrm{n}} \frac{\Gamma(\mathrm{a}+\mathrm{n}) \Gamma(2 \mathrm{n}+\mathrm{a}-1)}{\mathrm{n} !(\mathrm{n}+\mathrm{a}-1)} \mathrm{t}^{(\mathrm{a}-2) / 2} \mathrm{e}^{-1 / 2 \mathrm{t}} \mathrm{y}_{\mathrm{n}}(\mathrm{t} ; \mathrm{a}, 1) \\
& \square \mathbb{q}_{p_{i}+1, q_{i}+2: r}^{u+2, v}\left[\left.z\right|_{(-\sigma-n, \lambda),(a-\sigma-1+n, \lambda), \ldots \ldots . .} ^{\ldots}\right],
\end{aligned}
$$

provided that $\operatorname{Re} \square<0, \operatorname{Re}(\mathrm{a} \square)<2, \sigma \neq-1,-2,-3, \ldots .$. and $|\arg \mathrm{z}|<(1 / 2) \square \mathrm{B}$, where $\mathrm{B}$ is givenby:

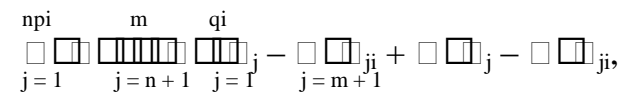

On specializing the parameters, I-function may be reduced to H-function, G-function, Lauricella's functions Legendre functions, Bessel functions, hypergeometric functions, Appell's functions, Kampe de Feriet's functions and several other higher transcendental functions. Therefore the result (15) is of general nature and may reduced to be in different forms, which will be useful in the literature on applied Mathematics and other branches.

\section{References}

[1]. Ahmad, S. S.: A Study of Hypergeometric Functions, Ph.D. Thesis, A.P.S. University, Rewa (M.P.), 1992.

[2]. Exton, H. On Orthogonal of Bessel Polynomials. Rev. Mat. Univ. parma (4) 12 (1986), 213-215.

[3]. Erdelyi, A.: A Table of Integral Transform, Vol.I, McGraw-Hill, New York, 1954

[4]. Erdelyi, A. et. al. Higher Transcendental Functions, Vol. 1 McGraw-Hill, New York, 1953.

[5]. Exton, H. Handbook of Hypergeometric Integrals, Ellis Horwood Ltd., Chichester, 1978. 